\title{
Effects of Strength-Based Approach Horticultural Therapy on Primary Students' Resilience
}

\author{
Mei-Lun Chen1, Li-Chen Lo' ${ }^{2}$, Shi-Jer Lou ${ }^{3 *}$ \\ ${ }^{1}$ Department of Tropical Agriculture and International Cooperation, National Pingtung University of Science and Technology, \\ Taiwan \\ ${ }^{2}$ Graduate Institute of Educational Administration, National Pingtung University, Taiwan \\ ${ }^{3}$ Department of Vocational and Technical Education, National Pingtung University of Science and Technology, Taiwan \\ Email: *c2114433@gmail.com
}

How to cite this paper: Chen, M.-L., Lo, L.-C. \& Lou, S.-J. (2018). Effects of Strength-Based Approach Horticultural Therapy on Primary Students' Resilience. Creative Education, 9, 2973-2991.

https://doi.org/10.4236/ce.2018.916223

Received: November 25, 2018

Accepted: December 26, 2018

Published: December 29, 2018

Copyright $(9) 2018$ by authors and Scientific Research Publishing Inc. This work is licensed under the Creative Commons Attribution International License (CC BY 4.0).

http://creativecommons.org/licenses/by/4.0/

cc) (i) Open Access

\begin{abstract}
This study aims to probe into effectiveness of strength-based approach horticultural group on elementary school students' resilience. The researcher used pretest and post-test experiment design and treated 36 students as subjects. There were respectively 18 subjects in experimental group and control group. Experimental group joined the group once a week, 120 minutes for each time and a total of 10 times. Measurement tool was Scale of Resilience for Primary School Students. Pretest was conducted in two groups one week before group activity, and post-test was conducted after the group activity, and track-test was conducted after the group activity three months later. As to research data, the researcher adopted descriptive statistics, analysis of covariance and Johnson-Neyman. Quantitative results show that the strength-based approach horticultural therapy significantly changes students' resilience in post-test, and significantly changes lower score students' resilience in track-test. This study suggests for future researchers to apply horticultural activities in education.
\end{abstract}

\section{Keywords}

Primary Students, Strength-Based, Horticultural Therapy, Resilience, Change Process

\section{Introduction}

Horticultural therapy is the engagement of a client in horticultural activities faci- 
litated by a trained therapist to achieve specific and documented treatment goals (American Horticultural Therapy Association, 2018). From the literature related to horticultural therapy found, horticultural therapy mostly focused on the operation through the process of physiological rehabilitation effect, or through the operation process to relieve pressure, or vocational training for special needs. However, there was rarely studying the use of horticulture as a medium for student counseling, especially for improving students' resilience.

The resilience is defined as "a dynamic course of adapting and presenting abilities successfully, even though the individual experiences have great adversity or difficulty" (Lee, Kwong, Cheung, Ungar, \& Cheung, 2009; Prince-Embury, 2008). Resilience is an important ability for the 5th and 6th grade students who are in stages of childhood that gradually enters puberty to overcome the dilemma, survive and develop.

The strengths perspective believe that humans have a self-righting tendency that allows children from adverse circumstances to move toward adult development under all but the most persistent, adverse life circumstances (Werner \& Smith, 1992). Smith (2006) based on strengths perspective proposed strength-based counseling model. This model provides specific steps that are easy for school counselors to adapt.

There are some studies which conduct a strength-based counseling for students to evaluate the efficacy of such intervention (Lee, 2011; Lin, 2013). However, there was rarely studying the use of strength-based counseling model for improving resilience.

The purposes of this study are to explore the effect of the strength-based approach of horticultural therapy groups, which can fill the gaps to the existing literature.

\subsection{Strengths-Based Counseling}

Several professions and movements laid the foundation for strength-based counseling: counseling psychology (Gelso \& Fretz, 1992); prevention movements and prevention research (Weissberg, Walberg, O’Brien, \& Kuster, 2003); positive psychology (Seligman \& Csikszentmihalyi, 2000); positive youth development (Larson, 2000); social work (Saleebey, 1992); solution-focused therapy (de Jong \& Berg, 2002); and the narrative therapy (White \& Epston, 1990). Smith (2006) integrated the above theory and proposed Strengths-Based Counseling, which believed that everyone has a positive ability to face setbacks and will recover from the adversity of life and have resilience factors.

Psychologists have emerged from the literature the following ten categories in assessing client' strengths and helping them in the counseling relationships, which are described briefly below (Smith, 2006): wisdom, emotional strengths, character strengths, creative strengths, encompassed relational and nurturing strength, educational strengths, individuals' analytical and cognitive strengths, individuals' work-related and provider strengths, individuals' ability to secure or 
make good use of social support and community strengths, survival skills.

Ten stages of strength-based counseling were proposed by Smith (2006), described below: creating the therapeutic alliance, identifying strengths, assessing presenting problems, encouraging and instilling hope, framing solutions, building strength and competence, empowering, changing, building resilience, evaluating and terminating. Strength-based therapist intentionally provides to effect behavioral change in the client rather than the problems, and give the client encouragement and hope to increase the motivation of clients to achieve the goal.

\subsection{Horticultural Therapy}

American Horticultural Therapy Association (AHTA, 2018) defines it as: "Horticultural therapy is the participation in horticultural activities facilitated by a registered horticultural therapist to achieve specific goals within an established treatment, rehabilitation, or vocational plan. Horticultural therapy is an active process which occurs in the context of an established treatment plan where the process itself is considered the therapeutic activity rather than the end product." Many studies use horticultural therapy to assist individuals in developing positive psychological emotions, behaviors, and social relationships that all have good effects (Chen et al., 2014). The environment of horticultural therapy can be divided into two categories: the first one is the "feeling garden", that is, participants from the touch, taste, hearing, visual and olfactory, with feelings and perception to get the effect. The second one is "the garden of operation", also called "healing garden" (Haubenhofer et al., 2010). Chen \& Huang (2005) divided the horticultural therapy activities into the following six categories: craft activities, group activities, visit activities, indoor planting, outdoor planting, and outdoor teaching.

\subsection{Resilience}

Looking back on the study of resilience in the past, we can see two paradigm shifts, firstly, to explore how the case shows the resilience in the face of adversity and difficulty from the perspective of strength-based; secondly, to regard resilience as a process and result of the interaction between individual characteristics and environment with the ecological system theory (Prince-Embury, 2008; Wang, Lu, \& Wu, 2010). Early researchers adopt the strength-based perspective, and define the resilience as "the strength of the individual's elasticity and the ability to adapt to the environment", believing that the person who showing resilience has a set of personal qualities and abilities, including free temperament, initiative, self-esteem, self-efficacy, problem-solving skills, goals, and ambitions (Anthony, 1987; Rutter, 1987). In recent years, with the study of the evolution of the model, the researchers tend to adopt the ecological system theory perspective, and emphasize resilience is a kind of complicated dynamic course, and define the resilience as "a dynamic course of adapting and presenting abilities successfully, even though the individual experiences great adversity or difficulty" 
(Lee, Kwong, Cheung, Ungar, \& Cheung, 2009; Prince-Embury, 2008). Combining the above scholars' view, resilience refers to the ability to adapt or recover quickly by using individual advantages and abilities with the resource and support of the environment when suffering from setbacks, stress, trauma, tragic events, threats or adversity.

\subsection{Related Research on Strengths-Based Counseling \& Resilience}

Lee's (2011) study. Fifteen high risk female students were randomly assigned into the experimental group $(n=7)$ and the control groups $(n=8)$, to receive the strength-based small group counseling with 50 minutes each time and a total of 8 times. Repeated evaluations of Inventory of Adolescent Resilience (LAR) for both experimental and control groups were conducted at three points of time: group session 4, 8 and one-month follow-up. There were no significant differences found between the two groups at session 4, 8, and 12 assessment on LAR. But compared the experimental group's pre-test and the session 12 assessment, there were significant differences on hope and optimism subscale of LAR ( $p$ $<.05)$.

Lin's (2013) study was designed with qualitative research, conducting four interviews to collect the impact of sexual trauma on five female adolescent survivors of sexual abuse prior to the counseling and the subjective experience based on 11 participations and 24 hours with strength-centered approach counseling group. The study findings are that effectively applied strength-centered approach and creative intervention techniques would impel strength development in members.

\subsection{Related Research on Horticultural Therapy \& Resilience}

Laaksoharju et al. (2012) treated 130 children of 7 - 12 year-old in 2008-2010 as subjects and recorded 37 times of 4-hour horticultural summer camp by qualitative method. The said researchers demonstrated that by horticulture, children could learn social skills and work ethics and establish friendship, affection and confidence.

Gatto et al. (2012) treated 104 students of Grade 4 and Grade 5 as subjects (34 subjects in experimental group and 70 subjects in control group) for horticultural activities which were held 90 minutes each week and lasted for 12 weeks. Before and after the activities, the researchers tested the motive of healthy diet and self-efficacy and demonstrated that two groups had significant difference in motive of healthy diet. Although they did not have significant difference in self-efficacy, experimental group made progress in post-test by 3.3 , in comparison to pretest. Control group only increased by 0.4 .

Chen et al. (2013) treated 31 Grade 3 students as subjects and the survey lasted for 15 weeks. Horticultural course lasted for 80 minutes every week. In computer course of 40 minutes every week, PowerPoint of horticultural activities was 
manufactured. One week before and after the activities, the subjects were tested by scale of attitude toward life. The said researchers realized that relationship between participants and themselves, others, environment and nature was significantly reinforced. They recognized their advantages, became more responsible. They had more harmonious interpersonal relationship and loved animals and plants more.

According to the above research literature, the following research questions are proposed:

1) After participating in the strength-based approach horticultural therapy group, are the members' resilience significantly higher than those who did not participate?

2) After participating in the strength-based approach horticultural therapy group, three months later, are the members' resilience significantly higher than those who did not participate?

\section{Research Methodology}

\subsection{General Background of Research}

The group program adopts a semi-structural design which boasts of established topics and related activities, and also concerns about the interconnection among members in group process as well as the recognition and participation of the group. In addition, the strength-based theory emphasizes the perception of various advantages and the growth of hope which require a warm interpersonal experience as a basis, while a positive group experience can bring this benefit. Program design is shown in Table 1: Activity pictures are shown in Figures 1-8.

\subsection{Sample of Research}

Before the group activities, researchers will talk with members about their will, motives and expectations to the group, therefore the participants in control group and the experimental group for this study is 18 people. The experimental group participates in the first or second group based on cooperative time, with 6 people in the first group and 12 in the second group.

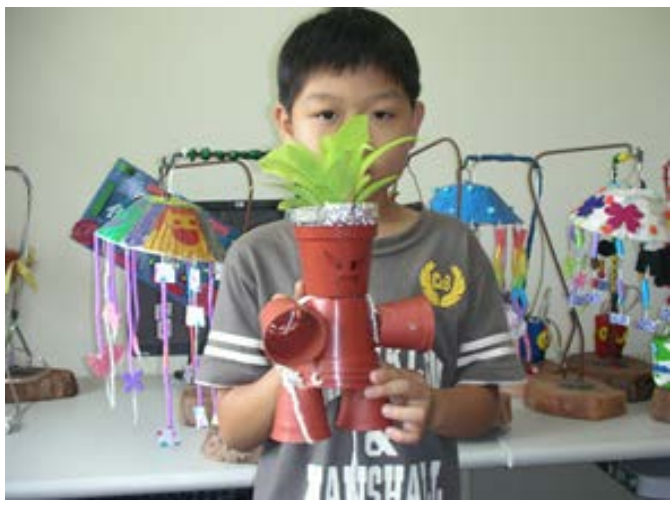

Figure 1. A small green man. 


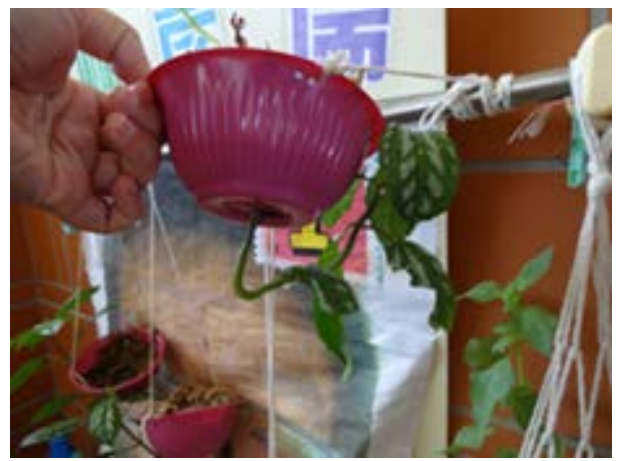

Figure 2. Downside planted.

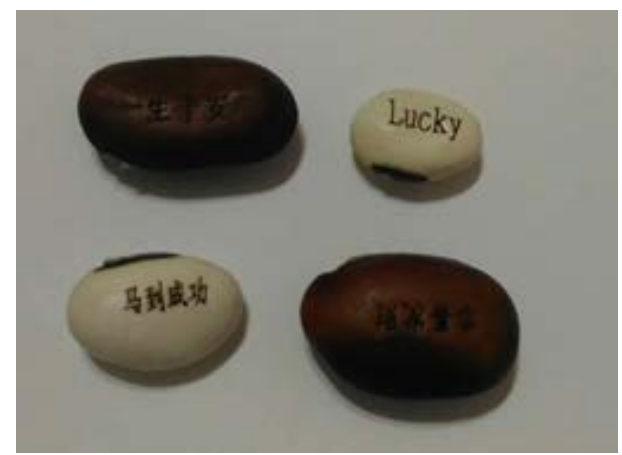

Figure 3. Magic beans.

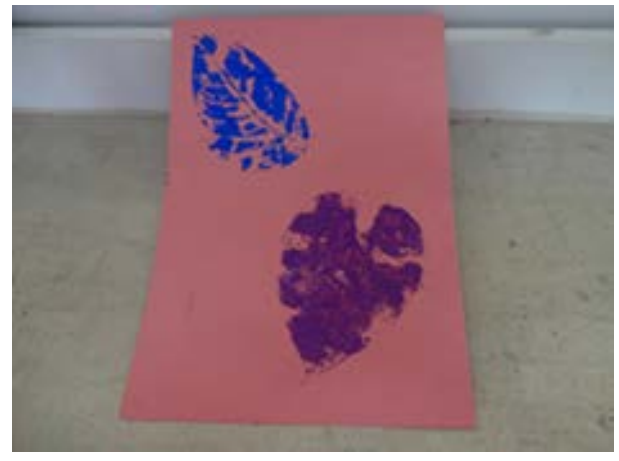

Figure 4. Leaves printing.

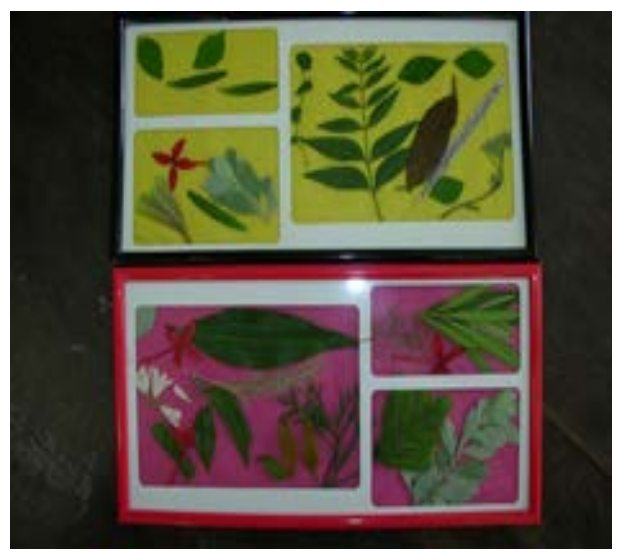

Figure 5. Flower pressing. 


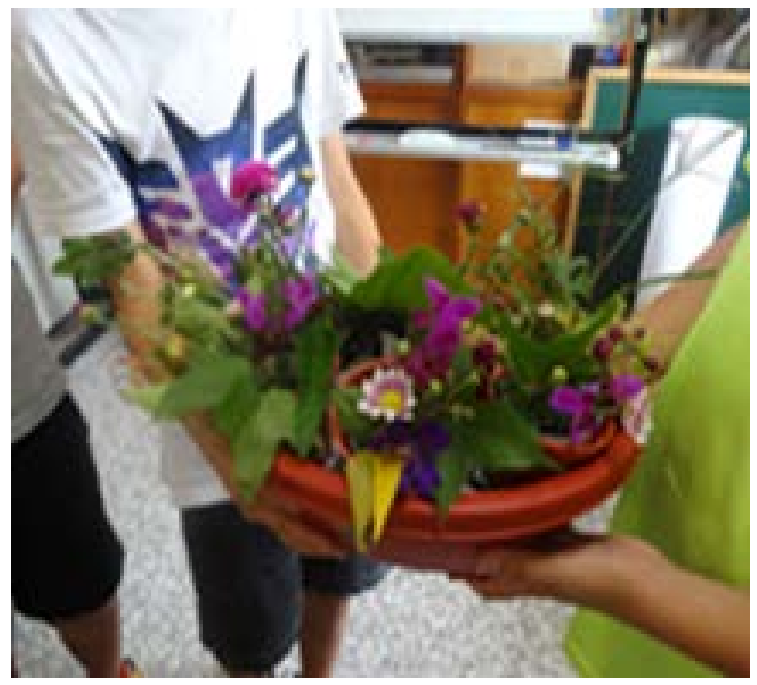

Figure 6. Combination potted plants.

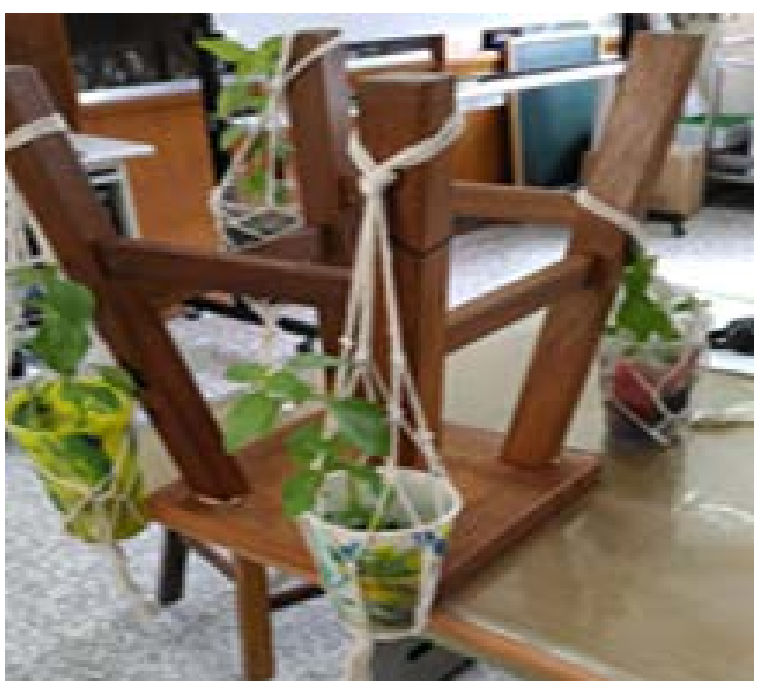

Figure 7. Hanging basket weaving.

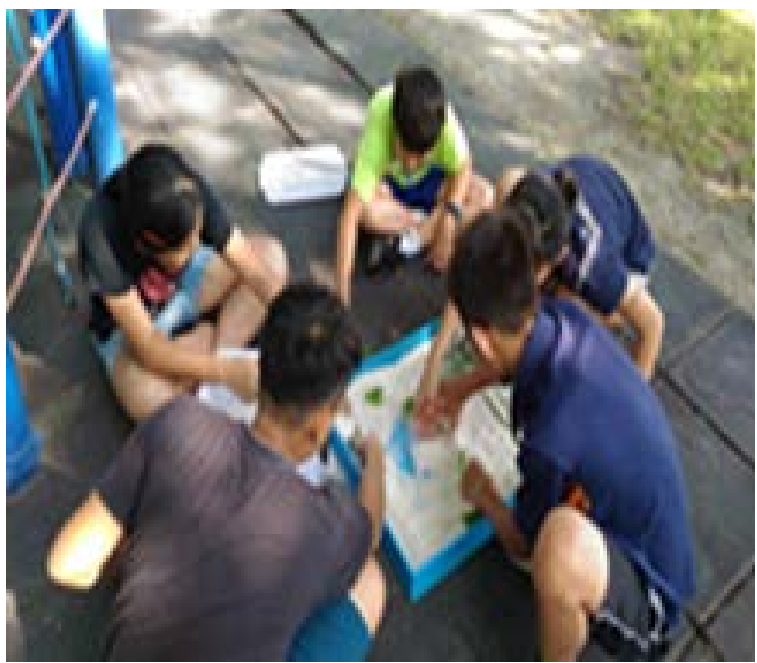

Figure 8. Group sandplay. 
Table 1. Strength-based approach horticultural therapy programs.

\begin{tabular}{|c|c|c|c|}
\hline Time & Group stage & Unit Objectives & Theme Activities \\
\hline 1 & $\begin{array}{l}\text { Creating the } \\
\text { therapeutic alliance }\end{array}$ & $\begin{array}{l}\text { 1) The establishment of cooperation, open group atmosphere. } \\
\text { 2) To clarify the objectives of the group and to assist members in } \\
\text { understanding the purpose and content of the group. } \\
\text { 3) Establish community norms that explain the principle of confidentiality. }\end{array}$ & $\begin{array}{l}\text { 1) Our promise } \\
\text { 2) Hatching bean sprouts }\end{array}$ \\
\hline 2 & $\begin{array}{l}\text { Identifying } \\
\text { strengths }\end{array}$ & $\begin{array}{l}\text { 1) To confirm the advantages of members } \\
\text { (physical, psychological, social, economic, etc.) } \\
\text { 2) To structure its life story } \\
\text { 3) Name and give meaning to the strengths you want to develop. }\end{array}$ & $\begin{array}{l}\text { 1) Seed stage } \\
\text { 2) A small green man }\end{array}$ \\
\hline 3 & $\begin{array}{l}\text { Assessing } \\
\text { presenting problems }\end{array}$ & To re-structure weaknesses or concerns into another advantage. & $\begin{array}{l}\text { 1) Magic crystal soil planting } \\
\text { 2) Downside planted }\end{array}$ \\
\hline 4 & $\begin{array}{l}\text { Encouraging and } \\
\text { instilling hope }\end{array}$ & $\begin{array}{l}\text { 1) Application advantages to achieve the goal. } \\
\text { 2) Encourage individual efforts and progress, not the result of effort. }\end{array}$ & 1) Handmade soap \\
\hline 5 & Framing solutions & $\begin{array}{l}\text { 1) Adjust the perspective of the problem. } \\
\text { 2) To find a solution to the problem. }\end{array}$ & $\begin{array}{l}\text { 1) Weeds are my teacher } \\
\text { 2) Magic beans }\end{array}$ \\
\hline 6 & $\begin{array}{l}\text { Building strength } \\
\text { and competence }\end{array}$ & $\begin{array}{l}\text { Self-made change of resource, environmental resource can also provide } \\
\text { assistance (emphasis on themselves and the environment). }\end{array}$ & $\begin{array}{l}\text { 1) Leaves printing } \\
\text { 2) Flower arrangement }\end{array}$ \\
\hline 7 & Empowering & $\begin{array}{l}\text { 1) Application of the advantages of a positive impact on life. } \\
\text { 2) Application advantages to the future change. }\end{array}$ & $\begin{array}{l}\text { 1) Flower arrangement } \\
\text { 2) Combination potted plants }\end{array}$ \\
\hline 8 & Changing & $\begin{array}{l}\text { 1) Change is a process rather than an independent event. } \\
\text { 2) Use the advantages to stimulate change. }\end{array}$ & $\begin{array}{l}\text { 1) Hanging basket weaving } \\
\text { 2) Knitting baskets }\end{array}$ \\
\hline 9 & Building resilience & $\begin{array}{l}\text { 1) The error is the opportunity to learn and does not represent failure. } \\
\text { 2) Have the ability to see the difficulties faced, the development } \\
\text { of good response skills. }\end{array}$ & $\begin{array}{l}\text { 1) Personal sand play } \\
\text { 2) Group sand play }\end{array}$ \\
\hline 10 & $\begin{array}{l}\text { Evaluating } \\
\text { and terminating }\end{array}$ & Confirm members change and give more encouragement. & $\begin{array}{l}\text { 1) Green bean soup } \\
\text { 2) Wish card and bless } \\
\text { card writing } \\
\text { 3) Reflection-my growth }\end{array}$ \\
\hline
\end{tabular}

\subsection{Instrument}

The "Scale of Resilience for Primary School Students" (SR) was created by Wang et al. (2010). The scale is consisted by 3 parts, including: personal basic information, external resource (ER) and inherent strengths (IS). Personal basic information has 3 items. External resource has 5 variables, a total of 20 items, including the parental resource (PR, questions 1 - 4), teacher resource (TR, questions 5-8), friend resource (FR, questions 9 - 12), neighborhood resource (NR, questions 13 - 16) and social model (SM, questions 17 - 20). Inherent strengths have 4 variables, a total of 22 items, including self-efficacy (SE, questions 21 - 24), optimism (OP, questions 25 - 28), interpersonal communication (IC, questions 29 34) and problem-solving ability (PS, questions 35 - 42). The potential variables reliability of measurement model of resilience for primary school students established are .82 (external resource) and .89 (inherent strengths), and the individual project reliability of the measurement index is between $.42-.84$, showing a very good reliability; the measurement model conforms to the standards of basic fitness degree, the overall model fitness degree and the internal model structure degree, showing a good construction validity; Moreover, it finds through the 
multi-group analysis that the constructions of scale of resilience for primary school students is consistent with verification of gender measurement identicalness and it also shows that it has the same meaning for this scale to measure the scores of resilience for primary school students.

\subsection{Procedures}

This study adopted "scale of resilience for primary school students" as measurement tools. Pretest (baseline $\mathrm{O}_{1}, \mathrm{O}_{2}$ ) was practiced on two groups one week before the group activity. After the said activity, post-test (baseline $\mathrm{O}_{3}, \mathrm{O}_{4}$ ) was conducted. Three months later, track-test (baseline $\mathrm{O}_{5}, \mathrm{O}_{6}$ ) was conducted too (Table 2).

The research structure of this study is shown in Figure 9.

\subsection{Data Analysis}

This study adopts pretest, post-test and track-test experiment design. By single-factor analysis of covariance of independent sample, it tests the significant difference of scores of experimental group and control group in pretest and post-test, as well as pretest and track-test. Independent variable is type of experimental group and dependent variable is score of post-test. Covariance is score of pretest. $\alpha$ is set as .05 for analysis. Before analysis of covariance (ANCOVA), the researcher conducts test of homogeneity of with-in regression coefficient. If it matches assumption of homogeneity of regression coefficient and analysis of covariance can be practiced. If it does not match the assumption of regression coefficient homogeneity, the Johnson-Neyman for statistical analysis will be adopted (Wu \& Tu, 2011). All quantitative data were calculated using SPSS (version 19.0, SPSS Inc., IBM Company, 2010).

Table 2. Quasi-experimental design of strength-based horticultural therapy programs.

\begin{tabular}{ccccccccccc}
\hline $\begin{array}{c}\text { Recruitment } \\
\text { Assignment }\end{array}$ & Group & Pre-test & $\mathrm{N}$ & Treatment & Post-test & $\mathrm{N}$ & $\begin{array}{c}\text { Defection } \\
\text { Rate }\end{array}$ & Track-test & $\begin{array}{c}\text { Defection } \\
\text { Rate }\end{array}$ \\
\hline $\mathrm{NR}$ & $\mathrm{EG}$ & $\mathrm{O}_{1}$ & 18 & $\mathrm{X}_{1}$ & $\mathrm{O}_{3}$ & 18 & $0 \%$ & $\mathrm{O}_{5}$ & 12 & $33 \%$ \\
$\mathrm{NR}$ & $\mathrm{CG}$ & $\mathrm{O}_{2}$ & 18 & & $\mathrm{O}_{4}$ & 18 & $0 \%$ & $\mathrm{O}_{6}$ & 12 & $33 \%$ \\
\hline
\end{tabular}

Note: Research Design (NR = Not randomly assigned; $E G=$ experiment group; $C G=$ experiment group; $X_{1}$ $=$ experimental treatment; Track $=$ three months later; $\mathrm{O}_{1}, \mathrm{O}_{2}=$ pretest; $\mathrm{O}_{3}, \mathrm{O}_{4}=$ post-test; $\mathrm{O}_{5}, \mathrm{O}_{6}=$ track-test).

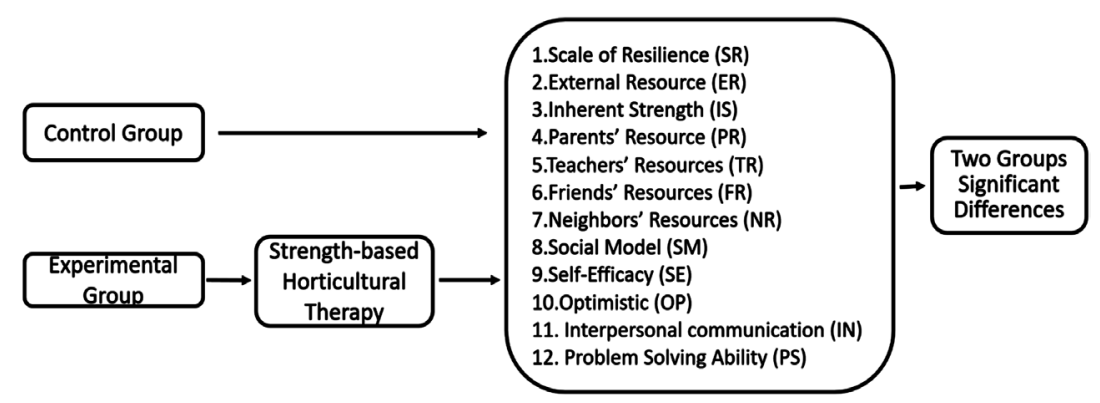

Figure 9. The research structure of this study. 


\section{Results of Research}

\subsection{The Effects of the Experimental Treatment on the Immediate Effect of Resilience}

\subsubsection{Analysis of Covariance (ANCOVA, Pretest \& Post-Test)}

Before analysis of covariance, the researcher conducts test of homogeneity of with-in regression coefficient. Results showed that $F$ of ER, IS, SR, PR, TR, TR, $\mathrm{NR}, \mathrm{SM}, \mathrm{SE}, \mathrm{OP}, \mathrm{IC} \& \mathrm{PS}$ is insignificant, $(F=.85,1.57, .34,1.51, .17, .01$, $1.95, .02, .01, .59, .02, p>.05)$. It matches assumption of homogeneity of regression coefficient, so that analysis of covariance can be practiced. $F$ of FR is significant $(F=6.8, p<.05)$, and it does not match the assumption of regression coefficient homogeneity. According to Table 3, after eliminating the effect of pretest

Table 3. Analysis of two groups "scale of resilience" (pretest \& post-test).

\begin{tabular}{|c|c|c|c|c|c|c|c|c|c|c|}
\hline \multirow{2}{*}{ Items } & \multirow{2}{*}{ Group } & \multirow{2}{*}{$\mathrm{N}$} & \multicolumn{2}{|c|}{ Pretest } & \multicolumn{2}{|c|}{ Post-test } & \multicolumn{2}{|c|}{$\begin{array}{c}\text { Estimated } \\
\text { Marginal Means }\end{array}$} & \multirow{2}{*}{$\begin{array}{c}\text { test of } \\
\text { homogeneity } \\
\text { of within } \\
\text { regression } \\
\text { coefficient }\end{array}$} & \multirow{2}{*}{$\begin{array}{c}\begin{array}{c}F \text { value } \\
\text { of }\end{array} \\
\text { ANCOVA }\end{array}$} \\
\hline & & & $M$ & $S D$ & $M$ & $S D$ & $M$ & $S E$ & & \\
\hline \multirow{2}{*}{ SR } & CG & 18 & 124.50 & 18.59 & 126.44 & 18.76 & $126.85^{\mathrm{a}}$ & 4.29 & \multirow{2}{*}{0.85} & \multirow{2}{*}{$6.75^{*}$} \\
\hline & EG & 18 & 127.00 & 21.65 & 143.02 & 19.30 & $142.62^{\mathrm{a}}$ & 4.29 & & \\
\hline \multirow{2}{*}{ ER } & CG & 18 & 61.44 & 10.73 & 62.33 & 9.42 & $62.17^{\mathrm{a}}$ & 2.14 & \multirow{2}{*}{1.57} & \multirow{2}{*}{3.10} \\
\hline & EG & 18 & 60.11 & 10.98 & 67.33 & 9.27 & $67.50^{\mathrm{a}}$ & 2.14 & & \\
\hline \multirow{2}{*}{ IS } & CG & 18 & 63.06 & 9.89 & 64.11 & 10.44 & $64.85^{\mathrm{a}}$ & 2.32 & \multirow{2}{*}{.34} & \multirow{2}{*}{$9.33^{* *}$} \\
\hline & EG & 18 & 66.89 & 11.61 & 75.68 & 10.50 & $74.94^{\mathrm{a}}$ & 2.32 & & \\
\hline \multirow{2}{*}{ PR } & CG & 18 & 12.39 & 3.01 & 12.25 & 2.07 & $12.77^{\mathrm{a}}$ & .61 & \multirow{2}{*}{1.51} & \multirow{2}{*}{.97} \\
\hline & EG & 18 & 11.61 & 3.42 & 13.58 & 3.07 & $13.62^{\mathrm{a}}$ & .61 & & \\
\hline \multirow{2}{*}{ TR } & CG & 18 & 11.89 & 3.09 & 12.83 & 2.79 & $13.19^{\mathrm{a}}$ & .43 & \multirow{2}{*}{0.17} & \multirow{2}{*}{.88} \\
\hline & EG & 18 & 13.11 & 2.22 & 14.11 & 1.78 & $13.76^{\mathrm{a}}$ & .43 & & \\
\hline \multirow{2}{*}{ FR } & CG & 18 & 13.22 & 3.34 & 12.78 & 2.69 & $12.57^{\mathrm{a}}$ & .64 & \multirow{2}{*}{$6.80^{*}$} & \multirow{2}{*}{ - } \\
\hline & EG & 18 & 11.44 & 2.41 & 12.22 & 2.69 & $12.43^{\mathrm{a}}$ & .64 & & \\
\hline \multirow{2}{*}{ NR } & CG & 18 & 11.61 & 2.20 & 11.94 & 2.36 & $12.11^{\mathrm{a}}$ & .54 & \multirow{2}{*}{0.01} & \multirow{2}{*}{3.24} \\
\hline & EG & 18 & 12.78 & 2.86 & 13.67 & 2.30 & $13.50^{\mathrm{a}}$ & .54 & & \\
\hline \multirow{2}{*}{ SM } & CG & 18 & 12.33 & 2.52 & 11.94 & 2.49 & $11.90^{\mathrm{a}}$ & .53 & \multirow{2}{*}{1.95} & 62 \\
\hline & EG & 18 & 11.17 & 3.37 & 13.78 & 1.93 & $13.82^{\mathrm{a}}$ & .53 & & \\
\hline & CG & 18 & 11.17 & 2.26 & 11.56 & 2.85 & $11.76^{\mathrm{a}}$ & .60 & & \\
\hline$\sigma_{L}$ & EG & 18 & 12.72 & 2.37 & 13.67 & 2.11 & $13.46^{\mathrm{a}}$ & .60 & 0.02 & ד \\
\hline $\mathrm{OP}$ & CG & 18 & 11.11 & 2.27 & 10.78 & 2.67 & $11.05^{\mathrm{a}}$ & .53 & 001 & $1077^{* *}$ \\
\hline & EG & 18 & 12.50 & 2.23 & 13.83 & 1.95 & $13.56^{\mathrm{a}}$ & .53 & & \\
\hline IC & CG & 18 & 18.28 & 3.23 & 17.89 & 2.76 & $17.86^{\mathrm{a}}$ & .59 & $0-50$ & $1225^{* *}$ \\
\hline & EG & 18 & 18.06 & 3.40 & 20.83 & 2.50 & $20.87^{\mathrm{a}}$ & .59 & 0.39 & 15.25 \\
\hline & CG & 18 & 22.50 & 3.75 & 23.89 & 4.34 & $24.05^{\mathrm{a}}$ & 1.01 & & \\
\hline & EG & 18 & 23.61 & 5.56 & 27.35 & 4.52 & $27.19^{\mathrm{a}}$ & 1.01 & & \\
\hline
\end{tabular}

n.s. $p>.05 ;{ }^{*} p<.05 ;{ }^{* *} p<.01$. 
score, in post-test of SR, SM, \& PS, experimental group is significantly higher than control group $(F=6.75,6.38,4.78, p<.05)$. In addition, in post-test of IS, OP, \& IC, experimental group is significantly higher than control group $(F=$ 9.33, 10.70, 13.25, $p<.01)$. However, in post-test of total scale of ER, PR, TR, $\mathrm{NR}, \& \mathrm{SF}$, two groups are not significantly different $(F=3.10, .97, .88,3.24,3.79$, $p>$.05). Thus, treatment significantly change students' SR, IS, SM, OP, IC, \& PS, but not for ER, PR, TR, NR, \& SE.

\subsubsection{Johnson-Neyman for Subscale of FR (Pre \& Post-Test)}

The results are obtained by using the "Johnson-Neyman" to process the subscale of FR of control group and the experimental group. Based on the intersection point and critical points of significant differences of regression line (Figure 10), the results are: Critical points of significant differences are 8.08 \& 15.15. Which presents that while the pretest score is below 8.08, the post-test of experimental group is significantly higher than that in the control group $(p<.05)$; while the pretest score is above 15.15, the post-test of control group is significantly higher than that in experimental group $(p<.05)$. In conclusion, while the score of pretest is lower than 8.08 , the experimental group is significantly better than control group.

\subsection{The Effects of the Experimental Treatment on the Persistent Effect of Resilience}

\subsubsection{Analysis of Covariance (ANCOVA, Pretest \& Track-Test)}

Before analysis of covariance, the researcher conducts test of homogeneity of with-in regression coefficient. Table 4 is tests of between-subjects effects. Results

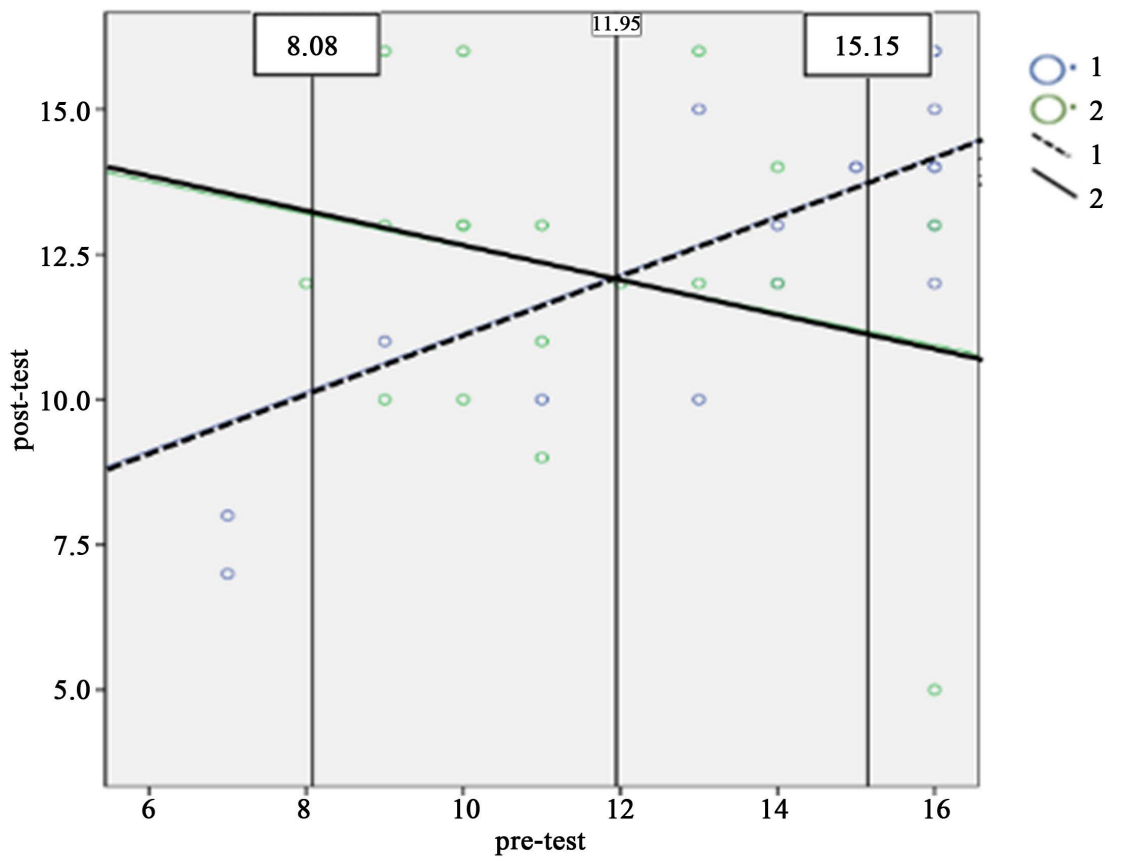

Figure 10. Significant differences of regression line of FR ( $1=$ Control Group; 2 = Experimental Group). 
Table 4. Analysis of two groups "scale of resilience" (pretest, track-test).

\begin{tabular}{|c|c|c|c|c|c|c|c|c|c|c|}
\hline \multirow{2}{*}{ Items } & \multirow{2}{*}{ Group } & \multirow{2}{*}{$\mathrm{N}$} & \multicolumn{2}{|c|}{ Pretest } & \multicolumn{2}{|c|}{ Track-test } & \multicolumn{2}{|c|}{$\begin{array}{c}\text { Estimated } \\
\text { Marginal Means }\end{array}$} & \multirow{2}{*}{$\begin{array}{l}\text { test of } \\
\text { homogeneity } \\
\text { of within } \\
\text { regression } \\
\text { coefficient }\end{array}$} & \multirow{2}{*}{$\begin{array}{l}F \text { value of } \\
\text { ANCOVA }\end{array}$} \\
\hline & & & $M$ & $S D$ & $M$ & $S D$ & $M$ & $S E$ & & \\
\hline \multirow{2}{*}{ SR } & CG & 12 & 124.00 & 17.07 & 123.17 & 25.17 & $122.97^{\mathrm{a}}$ & 6.49 & \multirow{2}{*}{$7.54^{*}$} & \multirow[b]{2}{*}{-} \\
\hline & EG & 12 & 122.17 & 22.95 & 143.17 & 19.17 & $143.36^{\mathrm{a}}$ & 6.49 & & \\
\hline \multirow{2}{*}{ ER } & CG & 12 & 62.08 & 10.37 & 59.17 & 12.25 & $58.89^{\mathrm{a}}$ & 3.41 & \multirow{2}{*}{4.15} & \multirow{2}{*}{3.72} \\
\hline & $\mathrm{EG}$ & 12 & 58.33 & 11.84 & 68.00 & 10.86 & $68.27^{\mathrm{a}}$ & 3.41 & & \\
\hline \multirow{2}{*}{ IS } & CG & 12 & 61.92 & 8.44 & 64.00 & 13.78 & $64.17^{\mathrm{a}}$ & 3.40 & \multirow{2}{*}{$7.21^{*}$} & \multirow{2}{*}{ - } \\
\hline & EG & 12 & 63.83 & 11.97 & 75.17 & 9.00 & $75.00^{\mathrm{a}}$ & 3.40 & & \\
\hline \multirow{2}{*}{ PR } & CG & 12 & 13.17 & 2.62 & 12.25 & 2.73 & $12.18^{\mathrm{a}}$ & 0.94 & \multirow{2}{*}{.15} & \multirow{2}{*}{1.15} \\
\hline & EG & 12 & 11.08 & 3.63 & 13.58 & 3.42 & $13.65^{\mathrm{a}}$ & 0.94 & & \\
\hline \multirow{2}{*}{ TR } & CG & 12 & 12.17 & 3.19 & 12.17 & 2.82 & $12.20^{\mathrm{a}}$ & 0.66 & \multirow{2}{*}{1.66} & \multirow{2}{*}{$5.92^{*}$} \\
\hline & EG & 12 & 12.42 & 2.07 & 14.50 & 1.68 & $14.47^{\mathrm{a}}$ & 0.66 & & \\
\hline \multirow[b]{2}{*}{ FR } & CG & 12 & 13.00 & 3.59 & 11.42 & 3.87 & $10.95^{\mathrm{a}}$ & 0.75 & \multirow[b]{2}{*}{$16.72^{* * *}$} & \multirow[b]{2}{*}{  } \\
\hline & EG & 12 & 11.58 & 2.11 & 13.83 & 2.25 & $14.30^{\mathrm{a}}$ & 0.75 & & \\
\hline \multirow{2}{*}{ NR } & CG & 12 & 11.50 & 2.15 & 10.33 & 2.81 & $10.26^{\mathrm{a}}$ & 0.87 & \multirow{2}{*}{3.28} & \multirow{2}{*}{$4.52^{*}$} \\
\hline & EG & 12 & 12.58 & 3.32 & 12.83 & 3.07 & $12.91^{\mathrm{a}}$ & 0.87 & & \\
\hline \multirow{2}{*}{ SM } & CG & 12 & 12.25 & 2.45 & 13.00 & 2.56 & $12.95^{\mathrm{a}}$ & 0.75 & \multirow{2}{*}{$8.44^{* *}$} & \\
\hline & EG & 12 & 10.67 & 3.58 & 13.25 & 2.42 & $13.30^{\mathrm{a}}$ & 0.75 & & \\
\hline & CG & 12 & 11.08 & 2.28 & 11.08 & 2.75 & $11.24^{\mathrm{a}}$ & 0.68 & & \\
\hline D & EG & 12 & 12.42 & 2.64 & 14.17 & 1.80 & $14.01^{\mathrm{a}}$ & 0.68 & $0 . / 0$ & - \\
\hline & CG & 12 & 10.75 & 2.14 & 11.83 & 2.37 & $12.16^{\mathrm{a}}$ & 0.64 & & \\
\hline$U P$ & EG & 12 & 12.00 & 2.22 & 13.67 & 2.43 & $13.34^{\mathrm{a}}$ & 0.64 & 2.00 & 1.03 \\
\hline & CG & 12 & 18.25 & 2.77 & 17.67 & 4.01 & $17.55^{\mathrm{a}}$ & 1.02 & {$\left[-24^{*}\right.$} & \\
\hline & EG & 12 & 17.17 & 3.04 & 20.33 & 2.87 & $20.45^{\mathrm{a}}$ & 1.02 & & \\
\hline Do & CG & 12 & 21.83 & 3.24 & 23.42 & 5.44 & $23.42^{\mathrm{a}}$ & 1.37 & & \\
\hline & EG & 12 & 22.25 & 6.15 & 27.00 & 3.67 & $27.00^{\mathrm{a}}$ & 1.37 & 1.10 & \\
\hline
\end{tabular}

n.s. $p>.05 ;{ }^{*} p<.05 ;{ }^{* *} p<.01 ;{ }^{* *} p<.001$.

showed that $F$ of ER, PR, TR, NR, OP, \& PS is insignificant, $(F=4.15, .15,1.66$, $3.28,2.00 \& 1.73, p>.05)$. It matches assumption of homogeneity of regression coefficient and analysis of covariance can be practiced.

$F$ of SR $(F=7.54, p<.05)$, IS $(F=7.21, p<.001)$, FR $(F=16.72, p<.001)$, SM $(F=8.44, p<.01)$, SE $(F=6.76, p<.05) \&$ IC $(F=5.24, p<.05)$ are significant, and they does not match the assumption of regression coefficient homogeneity. Hence, analysis of covariance is not adopted.

According to Table 4, after eliminating the effect of pretest score, in track-test of TR, \& NR, experimental group is significantly higher than control group $(F=$ 
$5.92,4.52, p<.05)$. However, in post-test of total scale of ES, PR, OP, \& PS, two groups are not significantly different $(F=3.72,1.15,1.65, \& 3.41, p>.05)$. Thus, treatment significantly change students' TR, \& NR, but not for ER, PR, OP, \& PS.

\subsubsection{Johnson-Neyman for SR, IS, FR, SM, SE \& IC (Pre \& Track-Test)}

The results are obtained by using the "Johnson-Neyman" to process SR of control group and the experimental group. Based on the intersection point and critical points of significant differences of regression line (Figure 11), the results are: Critical points of significant differences are 126.25, which presents that while the pretest score is below 126.25, the track-test of experimental group is significantly higher than those in the control group $(p<.05)$.

Based on the intersection point and critical points of significant differences of IS regression line (Figure 12), critical point of significant differences is 64.09 , which presents that while the pretest score is below 64.09, the track-test of experimental group is significantly higher than those in the control group ( $p$ $<.05)$.

Based on the intersection point and critical points of significant differences of FR regression line (Figure 13), critical point of significant differences is 13.07, which presents that while the pretest score is below 13.07, the track-test of experimental group is significantly higher than those in the control group ( $p$ $<.05)$.

Based on the intersection point and critical points of significant differences of SM regression line (Figure 14), critical points of significant differences are 9.54 \& 15.51. Which presents that while the pretest score is below 9.54, the track-test of experimental group is significantly higher than those in the control group ( $p$ $<.05$ ); while the pretest score is above 15.51, the track-test of control group is significantly higher than that in the experimental group $(p<.05)$.

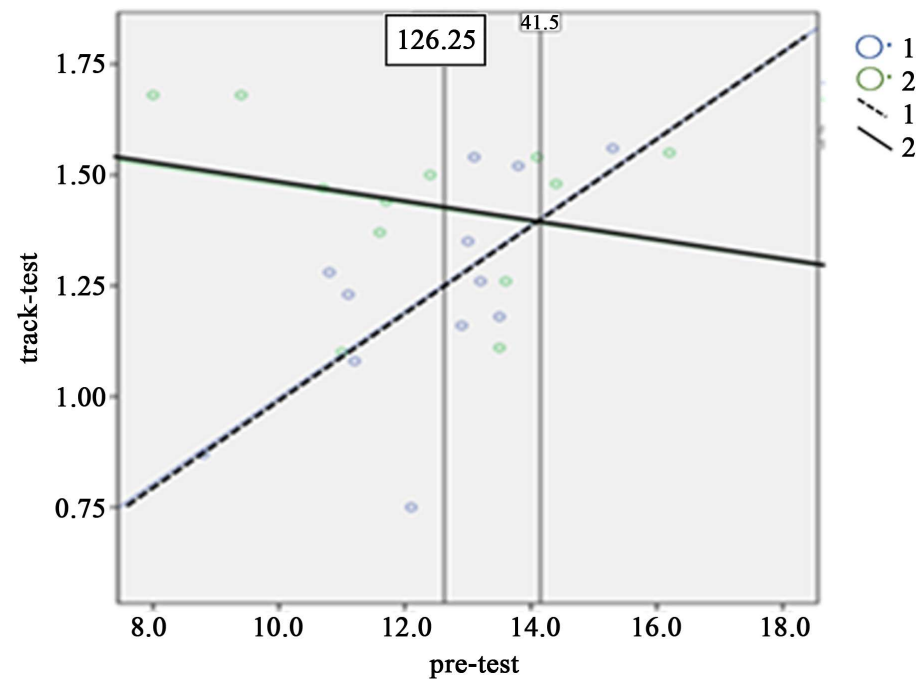

Figure 11. Significant differences of regression line of SR ( $1=$ Control Group; $2=$ Experimental Group). 


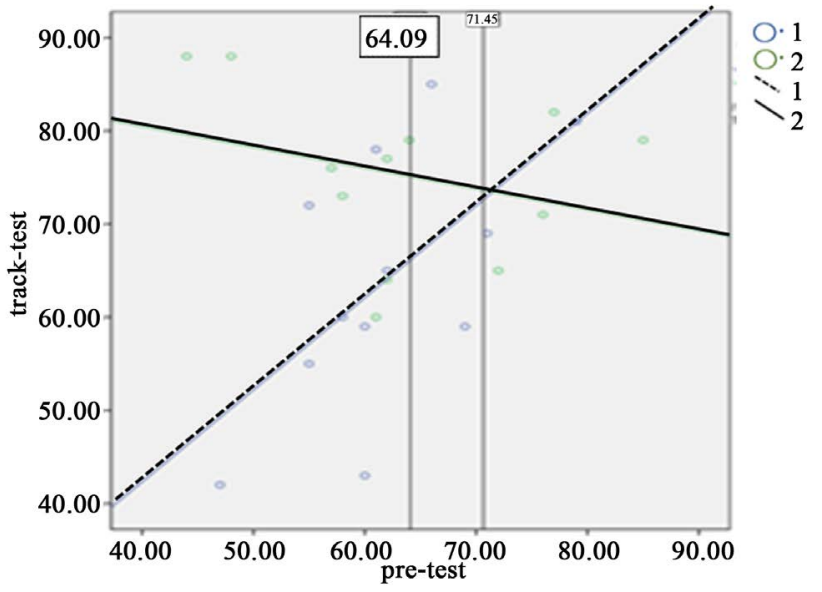

Figure 12. Significant differences of regression line of IS $(1=$ Control Group; $2=$ Experimental Group).

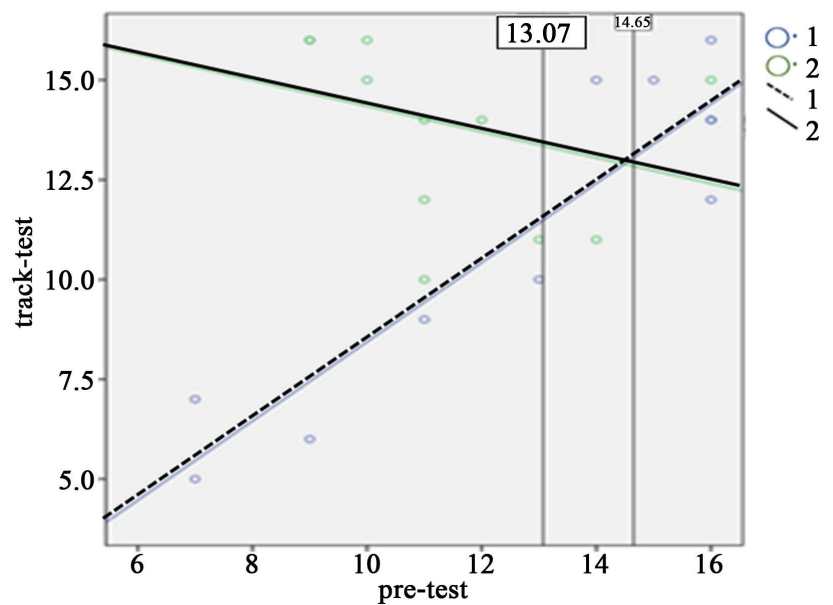

Figure 13. Significant differences of regression line of FR ( $1=$ Control Group; 2 = Experimental Group).

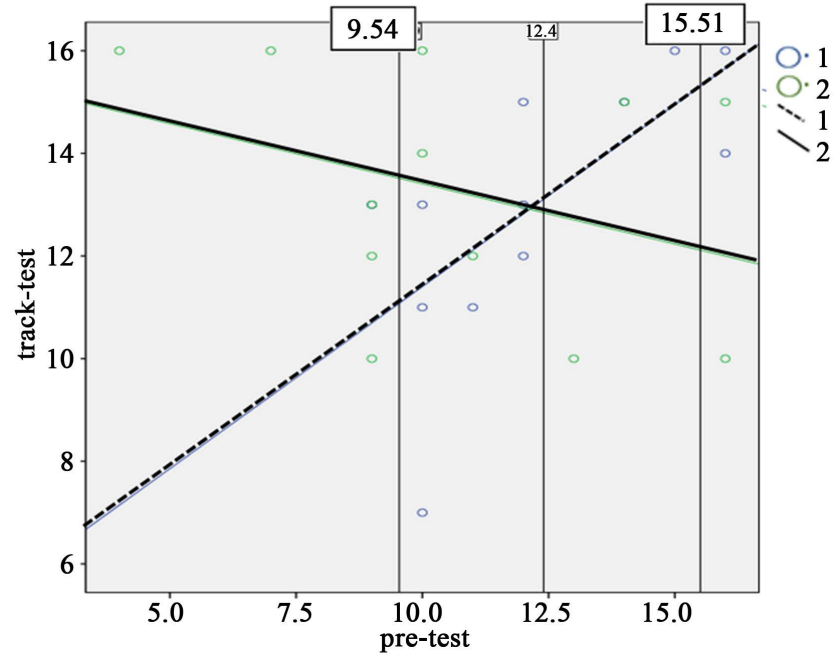

Figure 14. Significant differences of regression line of SM (blue = Control Group; green = Experimental Group). 
Based on the intersection point and critical points of significant differences of SE regression line (Figure 15), critical point of significant differences is 12.56 , which presents that while the pre-test score is below 12.56, the track-test of experimental group is significantly higher than those in the control group ( $p$ $<.05)$.

Based on the intersection point and critical points of significant differences of IC regression line (Figure 16), critical point of significant differences is 17.87, which presents that while the pretest score is below 17.87, the track-test of experimental group is significantly higher than those in the control group ( $p$ $<.05)$.

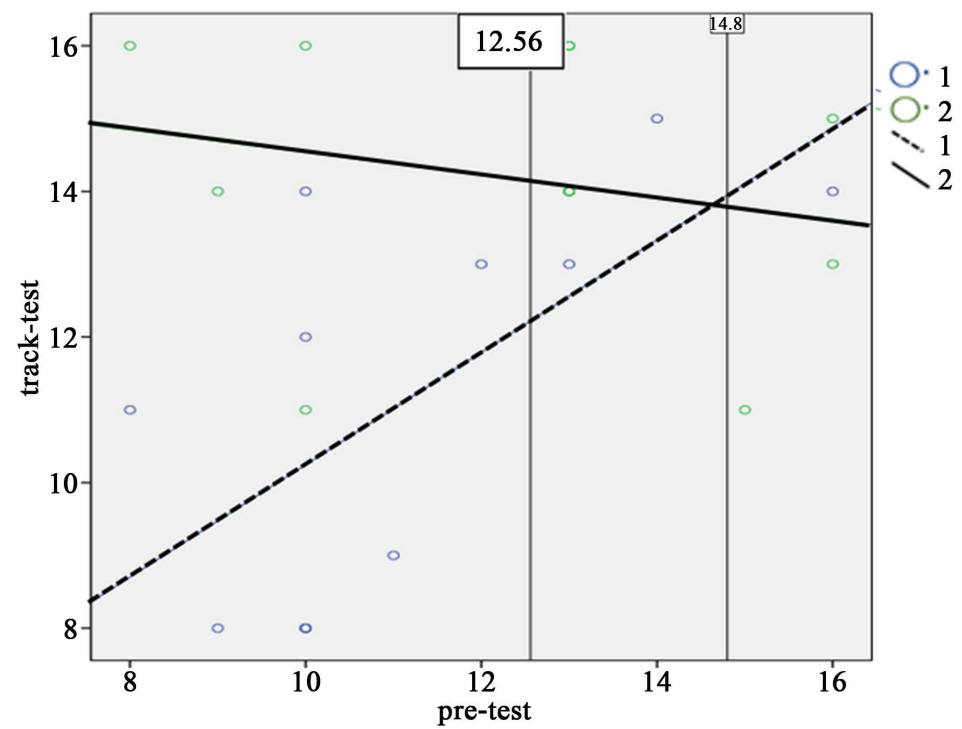

Figure 15. Significant differences of regression line of SE (blue = Control Group; green = Experimental Group).

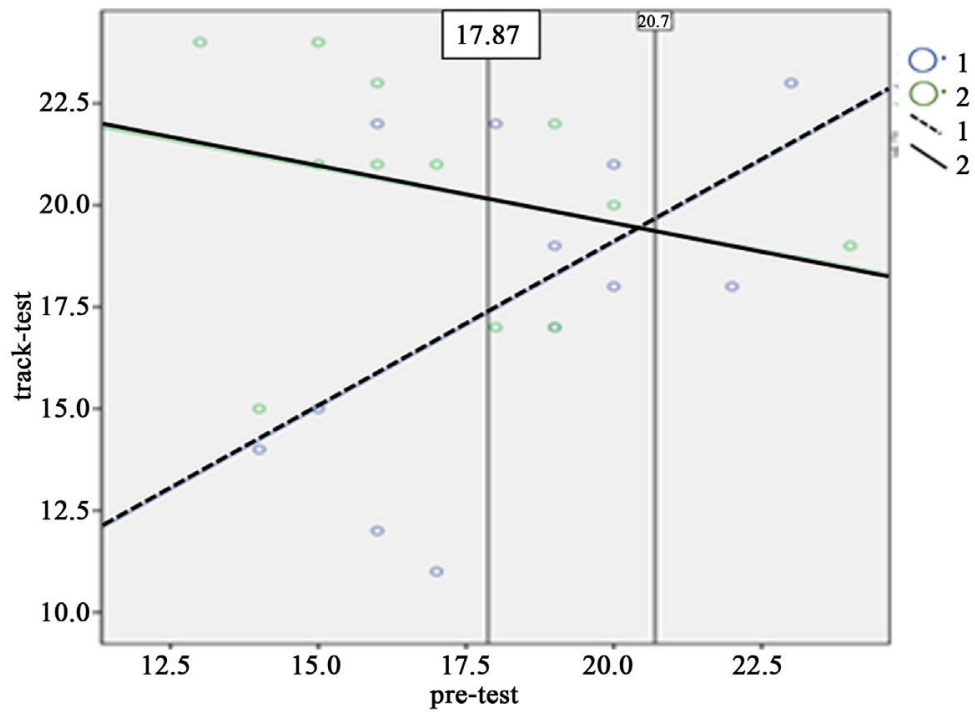

Figure 16. Significant differences of regression line of IC (blue = Control Group; green = Experimental Group). 


\section{Discussion}

A main purpose of resiliency is to help individuals successfully positive adapt and display ability when they encounter adversity or difficulties (Lee, Kwong, Cheung, Ungar, \& Cheung, 2009; Prince-Embury, 2008). Therefore, if it is able to assist low-score participants in pretest of resilience scale make significant progress in post-test and track test in virtue of the experimental intervention, this study is more meaningful. Therefore, in the following discussion, the "covariate analysis" effect and low-score group in "Johnson-Neyman" will be classified as one. The analysis results can be divided into four types from table above: one is the post-test and track test are effective; the second one is the post-test and track test are invalid; the third one refers the post-test is invalid and track test is effective; the fourth one is the post-test and track test are invalid. The analysis is as following:

\subsection{Items Which Post-Test and Track Test Are Valid}

"Resilience scale", "inherent strength", "friend resource", "social model" and "interpersonal communication" are valid to low score groups' post-test and track test.

Valid "Resilience scale" shows that the experiment has immediate effect and has a lasting effect on the pretested low score students.

"Inherent strength", "friend resource", "social model" and "interpersonal communication" are valid, showing that this study is helpful for members to perceive the external advantages (friends and social resource),and promoting internal recovery factor (interpersonal communication skill).

The study results are in line with the hypothesis of advantage consultative model on the effectiveness, and is able to help members identify internal and external advantages, cultivate social skills and good coping skills (Smith, 2006). They are also meeting the opinion that horticultural therapy is of social and cognitive benefits (Sempik, Aldridge, \& Becker, 2003).

\subsection{Items Which Post-Test Are Valid and Track-Test Invalid}

Although "optimism" and "problem-solving ability" produce immediate effect after experimental intervention, there is no a lasting effect after three months of experiment. Possible reasons affecting this study are as follows: Horticulture operation can produce positive emotions, and when self-confidence and happiness increase, behaviors can be adjusted into socially acceptable patterns, which stimulating enthusiasm for future life and meeting the instincts of creation (Chen, Lou, \& Shih, 2013; Relf, 1973). As the strength-based theory, empowerment can increase results in group processes. So immediate improvement will be produced in "optimistic" facets for members; besides, "problem-solving ability" produces significant effects in post-test. However, the promotion of "optimism" and "problem-solving ability" rests with the group operation. If members neglect 
practice or internalization, it is easy to bring the "intrinsic strengths" back to the original state. So there is no result in track test.

\subsection{Items Which Post-Test Are Invalid and Track Test Are Valid}

"Teacher resource", "neighborhood resource" and "self-efficacy" fail to produce immediate effects, but there is a lasting effect. The possible reasons affecting this study are as follows: self-efficacy" skills learned in group need a period of time for slow digestion, precipitation and collectivization. "Teacher resource" and "neighborhood resource" followed individual maturity and which brought different view for external resource.

\subsection{Invalid Post-Test and Track-Test Items}

The post-test and track test of "parental resource" are invalid. The reason may be both groups are deeply affected by their parents, so the influence that group can give is weak. Because of the effect of "Parental resource", post-test and tract-test of "external resource" is also invalid.

\section{Conclusion}

The post-test results of 6 variables (total scale of "resilience", "inherent strength", "social models", "optimism", “interpersonal communication" and "problem solving ability") in experiment are significantly better than those in the control group. In addition, the post-test results for pretest low scorers in friend resource in the experimental group are significantly better than those in the control group.

The track results in "teacher resource" and "neighborhood resource" in the experimental group are significantly better than those in control group. In addition, the track test results for pre-test low scorers in six variables ("total scale of resilience", "inherent strength", "friend resource", "social model", "self-efficiency" and "interpersonal communication") in the experimental group are significantly better than those in the control group.

In summary, it shows from total scores of "scale of resilience for primary school students" that there are more significant progresses in post-test and track test in the experimental group than those in the control group, presenting that strength-based approach horticultural therapy exerts a positive influence on resilience.

In this study, forward suggestions are: the strength-based approach horticultural therapy should be applied into training of primary school counseling personnel, and be applied into counseling work in primary school campuses to assist students enhancing their strength ability and resilience.

\section{Conflicts of Interest}

The authors declare no conflicts of interest regarding the publication of this paper. 


\section{References}

American Horticultural Therapy Association, AHAT (2018). Horticultural Therapy-Definitions and Positions. http://www.ahta.org/ahta-definitions-and-positions

Anthony, E. J. (1987). Risk, Vulnerability, and Resilience: An Overview. New York: Guilford.

Chen, H. M., \& Huang, Y., L. (2005). The Theory and Application of Horticultural Therapy. Journal of the Chinese Society for Horticultural Science, 51, 135-144.

Chen, M. L., Lou, S. J., \& Shih, R. C. (2013). Effects of Integrating Garden-Based Learning and E-Learning into Life Education. Life Science Journal, 10, 2037-2047.

Chen, M. L., Lou, S. J., Tsai, W. F., \& Tsai, C. C. (2014). A Study of the Impact of Horticultural Activities on Primary School Children's Self-Concept, Well-Being and Effectiveness. Journal of Baltic Science, 13, 637-649.

de Jong, P., \& Berg, I. K. (2002). Interviewing for Solutions. Pacific Grove, CA: Brooks/Cole.

Gatto, N. M., Ventura, E. E., Cook, L. T., Gyllenhammer, L. E., \& Davis, J. N. (2012). LA Sprouts: A Garden-Based Nutrition Intervention Pilot Program Influences Motivation and Preferences for Fruits and Vegetables in Latino Youth. Journal of Academy of Nutrition and Dietetics, 122, 913-920. https://doi.org/10.1016/j.jand.2012.01.014

Gelso, C. G., \& Fretz, B. R. (1992). Counseling Psychology. Fort Worth, TX: Harcourt Brace Jovanovich.

Haubenhofer, D. K., Elings, M., Hassink, J., \& Hine, R. E. (2010). The Development of Green Care in Western European Countries. Explore, 6, 106-111. https://doi.org/10.1016/j.explore.2009.12.002

Laaksoharju, T., Rappe, E., \& Kaivola, T. (2012). Garden Affordances for Social Learning, Play, and for Building Nature-Child Relationship. Urban Forestry \& Urban Greening, 11, 195-203. https://doi.org/10.1016/j.ufug.2012.01.003

Larson, R. W. (2000). Toward a Psychology of Positive Youth Development. American Psychologist, 55, 30-37. https://doi.org/10.1037/0003-066X.55.1.170

Lee, H. W. (2011). Outcome Study of a Strength-Based Small Group Counseling for High Risk Junior High Female Student. (Unpublished Doctoral Dissertation). Taipei: Nation Taiwan Normal University.

Lee, T., Kwong, W., Cheung, C., Ungar, M., \& Cheung, M. Y. L. (2009). Children's Resilience-Related Beliefs as a Predictor of Positive Child Development in the Face of Adversities: Implications for Interventions to Enhance Children's Quality of Life. Social Indicators Research Online. https://doi.org/10.1007/s11205-009-9530-x

Lin, Y. Y. (2013). Exploring the Sexual Abused Female Adolescent Survivors' Perceptions of Their Change Process in Strength-Centered Approach Counseling Group. (Unpublished Doctoral Dissertation). Changhua City: National Changhua University of Education.

Prince-Embury, S. (2008). Translating Resiliency Theory for Assessment and Application in Schools. Canadian Journal of School Psychology, 23, 4-10. https://doi.org/10.1177/0829573508316560

Relf, P. D. (1973). Horticulture: A Therapeutic Tool. Journal of Rehabilitation, 39, 27-29.

Rutter, M. (1987). Psychosocial Resilience and Protective Mechanisms. American Journal of Orthopsychiatry, 57, 316-331. https://doi.org/10.1111/j.1939-0025.1987.tb03541.x

Saleebey, D. (1992). The Strengths Perspective in Social Work Practice. New York: Longman. 
Seligman, M. E., \& Csikszentmihalyi, M. (2000). Positive Psychology: An Introduction. American Psychologist, 55, 5-14. https://doi.org/10.1037/0003-066X.55.1.5

Sempik, J., Aldridge, J., \& Becker, S. (2003). Social and Therapeutic Horticulture: Evidence and Messages from Research. Loughborough, England: Loughborough University (In Association with Thrive).

Smith, E. J. (2006). The Strength-Based Counseling Model. The Counseling Psychologist, 34, 13-79. https://doi.org/10.1177/0011000005277018

Wang, S. F., Lu, T., H., \& Wu, Y. Y. (2010). Evaluation the Measurement Invariance of the Scale of Resilience for Primary School Student. Journal of Educational Measurement and Statistics, 18, 23-45.

Weissberg, R. P., Walberg, H. J., O'Brien, M. U., \& Kuster, C. B. E. (2003). Long-Term Trends in the Well-Being of Children and Youth. Washington DC: Child Welfare League of American Press.

Werner, E. E., \& Smith, R. S. (1992). Overcoming the Odds: High Risk Children from Birth to Adulthood. Ithaca, NY: Cornell University Press.

White, M., \& Epston, D. (1990). Narrative Means to Therapeutic Ends. New York: Norton.

Wu, M. L., \& Tu, J. T. (2011). SPSS \& the Application and Analysis of Statistics. Taipei: Wu-Nan. 